\title{
Medication adherence in the management of nocturia: challenges and solutions
}

\author{
This article was published in the following Dove Press journal: \\ Patient Preference and Adherence \\ 13 January 2015 \\ Number of times this article has been viewed
}

\author{
Ravishankar Jayadevappa ${ }^{1-3}$ \\ Diane K Newman ${ }^{2}$ \\ Sumedha Chhatre ${ }^{4}$ \\ Alan J Wein ${ }^{2}$ \\ 'Department of Medicine, Perelman \\ School of Medicine, ${ }^{2}$ Division of \\ Urology, Department of Surgery, \\ Perelman School of Medicine, \\ ${ }^{3}$ Leonard Davis Institute of \\ Health Economics, ${ }^{4}$ Department \\ of Psychiatry, Perelman School of \\ Medicine, University of Pennsylvania, \\ Philadelphia, PA, USA
}

Objective: Nocturia affects millions of men and women. No prior reviews or meta-analyses have explored the issue of adherence in nocturia patients. The objective of our study was to examine the attributes and their interaction that might impact pharmacological adherence in nocturia care using a conceptual model of adherence.

Materials and methods: A literature search of the Medline, PubMed, Embase, PsycInfo, and CINAHL databases for studies published between January 1990 and June 2014 was conducted. We developed a conceptual model in order to facilitate our review.

Results: Currently, multiple treatment options for nocturia exist, depending on the underlying cause. Adherence to nocturia treatment and outcomes are complex and intertwined, and nonadherence to nocturia treatment is common. In 15 studies meeting eligibility criteria, behavioral and pharmacologic interventions for nocturia were associated with reduced nocturia symptoms. Urinary symptoms that are associated with nocturia need individualized management depending on renal and hepatic function, medical comorbidities, and ongoing medication use in a patient. Another important factor related to adherence is the bother. Although nocturia is defined as nighttime-voiding frequency of one or more, not all persons may find this bothersome. The degree of bother is subjective, and may change from person to person. However, there is no information related to the association between bother and adherence to medication or behavioral treatments for nocturia. Medication dosing convenience, preference, and cost play important roles in adherence. We present a patient-centered conceptual model that brings together the various dimensions of medication adherence for nocturia.

Conclusion: Few studies have explored adherence to medication and related factors in the care of nocturia. Our conceptual model can aid development of interventions to improve adherence to nocturia medications.

Keywords: nocturia, adherence, overactive bladder, medication, bother, preference

\section{Introduction}

Nocturia is a highly prevalent and bothersome urologic symptom. ${ }^{1}$ It is defined by the International Continence Society as "the complaint that the individual has to wake at night one or more times to void". ${ }^{2}$ However, measure of bother caused by nocturia is not considered in this definition. Also, no differentiation is made between getting up in the night because of a feeling of the need to urinate versus getting up for some other reason. ${ }^{1,3,4}$ Among persons living at home, between 15\% to 30\% report symptoms of nocturia. This range is $30 \%-50 \%$ for those living in assisted living or acute-care facilities, or in nursing homes. ${ }^{5-7}$ The prevalence of nocturia increases with age, and is high in older men. ${ }^{8}$ In a systematic review, it was observed that $68.9 \%-93 \%$ of men in their 70 s and 80 s had void frequency of once per night, and 29\%-59.3\% had a minimum of two voids per night. ${ }^{5-7}$ Globally, persons from various ethnicity and nationality experience a high prevalence of nocturia..$^{5-7}$ Among the elderly, the prevalence of nocturia
Correspondence: Ravishankar Jayadevappa

Department of Medicine, Perelman School of Medicine, University of Pennsylvania, 224 Ralston-Penn Center, Philadelphia, PA 19104-2676, USA

Email jravi@mail.med.upenn.edu 
is higher compared to the prevalence of chronic diseases like coronary artery disease or asthma. However, current knowledge regarding nocturia is somewhat limited. Despite embarrassment, sleep disturbance, bother, and risk of falls, nocturia is often thought of as a usual aging-related process. Women seldom discuss nocturia with their physicians. Based on its pathophysiology, five important contributing factors of nocturia are: 24-hour polyuria or overall increase in urine production, increase in nighttime urine production or nocturnal polyuria, reduced bladder capacity, sleep disturbance, and circadian clock disorders. The reasons for reduced bladder capacity can be many, such as benign prostatic hyperplasia with detrusor overactivity and/or elevated postvoid residual volume, or overactive bladder. ${ }^{2,69,10}$

Nocturia is a bothersome urinary symptom, and can cause substantial impairment to the health and quality of life of a person. Fragmented sleep cycles due to nocturia can negatively impact the quality of sleep, resulting in daytime tiredness. ${ }^{11-15}$ Nocturnal enuresis, which affects up to $15 \%$ of children less than 15 years of age, has been shown to be associated with abnormal sleep patterns. ${ }^{16-20}$ Nocturia is also associated with falls and fall-related morbidity, as well as mortality. Nocturia may lead to lower work productivity and add to the overall burden on society. ${ }^{12,14}$ Although traditionally nocturia was considered one among the several urinary tract symptoms that are caused by dysfunction of the lower urinary tract, because of its multidimensional etiopathogenesis, it is now recognized as a distinct clinical condition. For treatments to be responsive to the probable causes, it is important to perform a proper evaluation of the nocturic patient. Treatment options for nocturia include lifestyle and behavioral strategies, pharmacotherapy, and surgery. ${ }^{21}$ Initial or first-line treatment for nocturia is behavioral therapy, which has been shown to be effective in reducing symptoms of nocturia. ${ }^{13,22-25}$

Adherence to medication is an important factor linked to the successful pharmacologic treatment of nocturia, and has implications for patients' quality of life and sleep pattern. Overall, adherence is:

The extent to which a person's behavior (in terms of taking medications, following diets, or executing lifestyle changes) coincides with medical or health advice. ${ }^{26}$

Ignoring adherence can result in incorrect dosage, changes in medication regimen, and escalated costs of care. ${ }^{6,27-30}$ In addition to underdiagnosis, lack of adherence is a major concern in nocturia treatment. Recent studies have confirmed that on average, half of the patients do not complete nocturia treatment. . $^{29,31-35}$
Multiple reasons for nonadherence to medication can be identified. Beliefs held by those who decline getting treated for a condition may appear to be inconsistent with those posited by the biomedical model. ${ }^{33}$ In addition to age, socioeconomic status, and education, other less explored patientcentered factors related to adherence are bother due to the condition, efficacy, and side effects of the medication, and patient preference, attitudes, and beliefs. ${ }^{12,21,33,36}$ Additionally, health care system-level and provider-level factors play a key role in both underdiagnosis of nocturia and treatment adherence. Therefore, adherence to nocturia treatment is a multifactorial construct that comprises patient-centered and provider-centered components.

\section{Conceptual model: medication adherence and patient-centered care}

The Institute of Medicine defines patient-centered care as "care that is respectful of and responsive to individual patient preferences, needs, and values". ${ }^{37}$ Our patient-centered conceptual model (Figure 1) brings together the various dimensions of medication adherence in nocturia. Our model is based on the Andersen model of health service use. The Andersen model postulates that the use of health services is a function of predisposition, ability, and need. ${ }^{26,38-40}$ The predisposing component relates to the inclination to use a certain quantity of health services. The enabling component identifies the specific conditions that make health services available to a person. Finally, the need factor refers to the health status. Our adaptation of the Andersen model uniquely takes into account the predisposing factors (age, race/ethnicity, and income), enabling factors (preference, attitude, and knowledge) and need factors (comorbidities, number of medications, and bother of nocturia symptoms). Health care that is patient-centered as well as evidence-based can facilitate improved treatment adherence and treatment outcomes. Medication adherence is dysfunctional among nocturia patients: it is affected by the level of bother, efficacy, and side effects of nocturia medication, disintegrated care, limited information regarding diseases, belief system, cognitive issues, age-related issues such as vision, hearing, and memory, and complicated medication regimens of patients with multiple chronic diseases. ${ }^{3,4}$ In some cases, a patient may add over-the-counter medications and other therapies to the ones prescribed by his/her doctor, and this in turn may exacerbate nocturia. Additionally, social and environmental factors can also influence medication adherence among nocturia patients. The main goal of our article was to offer an overview of the issue of adherence to medication in 


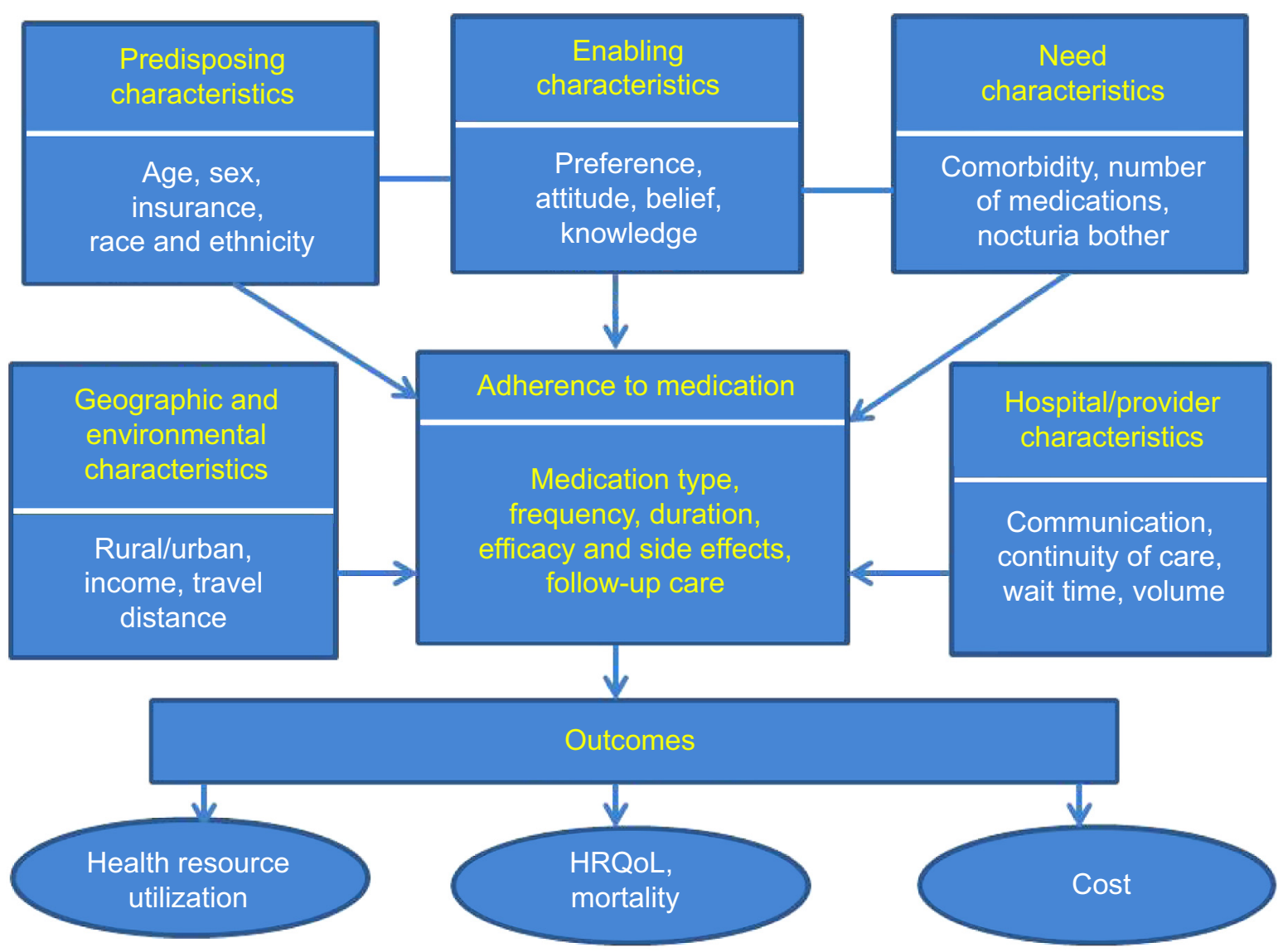

Figure I Conceptual model: adherence to nocturia medication.

Abbreviation: HRQoL, health-related quality of life.

the management of nocturia, and present a conceptual model to guide the adherence research in nocturia.

\section{Materials and methods}

We conducted a search of the electronic versions of the Medline, PubMed, PsycInfo, and CINAHL databases to obtain English-language articles that were published between 1990 and 2014. We used "nocturia", "adherence", "attitude", "treatment", and related terms as keywords in our search. Next, we selected articles related to medication adherence and comprehensive strategies for improving adherence to medication. The authors independently reviewed the abstracts. Next, the full text of relevant publications was read to examine whether the study used original data from patients and examined links between nocturia and adherence to medication. Case reports, review articles, and studies in laboratory settings were excluded from the analysis.

\section{Results}

Behavioral therapy is first-line therapy for nocturia, followed by pharmacotherapy with or without behavioral therapy. ${ }^{1}$
However, there is little information regarding bother, acceptability, and adherence to different components of behavioral therapies, which may depend on a tradeoff between the effectiveness versus inconvenience of such therapies. Adherence to medication among nocturia patients is weak. Studies show that only half of chronically ill older adults adhere to the medication regimens prescribed by their health care providers. ${ }^{6,26,41,42}$ The reasons can be cognitive impairment, comorbidities, access-related barriers such as cost and transportation, personal beliefs, preferences, and attitudes, and communication between patients and providers. ${ }^{6,26,41,43-46}$ There exists very little research related to medication adherence in nocturia patients. In Table 1, we provide a brief overview of some of the studies related to adherence among patients with lower urinary tract symptoms. It is important to note that most of the studies were related to overactive bladder. Based on the conceptual model, we summarized the results of the literature into five broad components that may influence medication adherence: health care-system and provider component, patient component, nocturia-condition component, nocturia-treatment component, and social and economic component. 
Table I Summary of studies included in the review

\begin{tabular}{|c|c|c|}
\hline Study & Study design & Overview \\
\hline Filipetto et al ${ }^{85}$ & $\begin{array}{l}\text { Mixed methods: qualitative interview } \\
\text { and cross-sectional survey }\end{array}$ & $\begin{array}{l}\text { Medication nonadherence is common, and is related to therapy } \\
\text { effectiveness and adverse effects. There exists a significant time } \\
\text { gap between symptom onset and diagnosis. }\end{array}$ \\
\hline Mauseth et $\mathrm{al}^{86}$ & Retrospective & $\begin{array}{l}\text { Discontinuation rate for anticholinergic drugs for overactive } \\
\text { bladder in women is high. Limited clinical effect and an } \\
\text { unacceptable adverse effect burden are the reasons } \\
\text { for discontinuation. }\end{array}$ \\
\hline Johnston et al ${ }^{80}$ & Retrospective & $\begin{array}{l}\text { Patients with diabetes were more persistent and adherent } \\
\text { to } O A B \text { medications and had higher odds of filling a second } \\
\text { medication prescription than patients without diabetes. }\end{array}$ \\
\hline Vecchioli Scaldazza et al ${ }^{43}$ & Randomized controlled study & $\begin{array}{l}\text { The cost of anticholinergics may be responsible for both early } \\
\text { discontinuation of treatment and incomplete adherence to } \\
\text { therapy, with unsatisfactory results on symptoms and an incorrect } \\
\text { assessment of the effectiveness of the drug by the urologist. }\end{array}$ \\
\hline Wagg et $\mathrm{al}^{74}$ & Retrospective & $\begin{array}{l}\text { Twelve months after the initial prescription, persistence rates } \\
\text { with pharmacotherapy in the context of } O A B \text { are generally low. }\end{array}$ \\
\hline Jundt et $\mathrm{a}^{84}$ & Cross-sectional survey & $\begin{array}{l}\text { Anticholinergic therapy is often discontinued by patients } \\
\text { and doctors. }\end{array}$ \\
\hline Sears et $\mathrm{a}^{32}$ & Retrospective & $\begin{array}{l}35 \% \text { of patients who received their medication free did not refill } \\
\text { their medication. }\end{array}$ \\
\hline Yeaw et al ${ }^{42}$ & Retrospective & $\begin{array}{l}\text { Adherence to prostaglandin eyedrops and } O A B \text { medications } \\
\text { was lower than that to cardiovascular, oral antidiabetic, } \\
\text { and oral osteoporosis therapies. }\end{array}$ \\
\hline Brubaker et a $\left.\right|^{44}$ & Cross-sectional survey & $\begin{array}{l}\text { Bother associated with the key OAB symptom, urgency, is a } \\
\text { predictor of discontinuation of treatment. Patients taking two } \\
\text { or more medications are less likely to discontinue. }\end{array}$ \\
\hline Benner et $\mathrm{al}^{\prime \prime}$ & Cross-sectional survey & $\begin{array}{l}\text { Expectations about treatment efficacy and side-effects are the } \\
\text { most important considerations in discontinuing } O A B \text { medications } \\
\text { for most patients. }\end{array}$ \\
\hline Pelletier et $\mathrm{al}^{30}$ & Retrospective & $\begin{array}{l}\text { Adherence among } O A B \text { therapy patients was low, with } 14 \% \\
\text { of patients achieving adherence of } 80 \% \text { or higher, and average } \\
\text { adherence was } 32 \% \text {. }\end{array}$ \\
\hline D'Souza et $\mathrm{al}^{27}$ & Retrospective & $\begin{array}{l}\text { Adherence was significantly better for extended-release than } \\
\text { immediate-release pharmacotherapy agents among managed care } \\
\text { plan enrollees. }\end{array}$ \\
\hline Balkrishnan et a $\left.\right|^{55}$ & Longitudinal cohort study & $\begin{array}{l}\text { Increased antimuscarinic MPR remained the strongest predictor } \\
\text { of decreased total annual health care costs }(5.6 \% \text { decrease } \\
\text { in annual costs with every } 10 \% \text { increase in MPR, } P<0.00 \text { I). }\end{array}$ \\
\hline Shaya et $\mathrm{a}^{46}$ & Retrospective & $\begin{array}{l}\text { Persistence rates are better for patients taking drugs } \\
\text { with once-daily dosing. }\end{array}$ \\
\hline Yu et $\mathrm{al}^{29}$ & Retrospective & $\begin{array}{l}\text { Only } 5 \% \text { patients exhibited }>80 \% \text { adherence during the } 6 \text {-month } \\
\text { follow-up-period. }\end{array}$ \\
\hline
\end{tabular}

Abbreviations: OAB, overactive bladder; MPR, medication-possession ratio.

\section{Health care-system and provider component}

Adherence is a complicated behavioral pattern, and is substantially affected by the health care system- and providerlevel factors. Though hospitals are dedicated to meeting the patients' needs, opportunities exist to make them more patient-centered. ${ }^{29,46-48}$ To operationalize patient-centered care effectively, hospitals and providers can concentrate on providing cohesive management, educating the patient, and sharing the available information related to nocturia. ${ }^{49}$
This highlights the necessity of bringing gradual changes to health care systems by responding to crucial care-related factors, such as costs, disparity, and access. These changes include the strategies, resources, and institutional and financial measures that determine if medical services are accessible, available, and acceptable. Adherence to nocturia medication is also affected by the communication between patient and provider regarding risks and benefits of treatment, proper use of medication, and finally, patient-friendly regimens. 


\section{Patient-related component}

Patient-related factors, such as bother due to nocturia, beliefs, attitude, preferences, and expectations, are vital for nocturiamedication adherence and treatment initiation. The issues of adherence and underdiagnosis of nocturia can be addressed by adopting a patient-centered care approach. In the context of health care, a patient-centered care model must incorporate preferences and needs of patients, encourage patient engagement in decision making, and adapt the treatment to improve outcomes. ${ }^{45}$ This relatively old concept poses unique challenges and offers opportunities in the continually altering field of medical care. ${ }^{6,11,40,44,47,48}$ Therefore, five dimensions of a patient-centered care model are: 1) understanding the patient and his/her medical condition, 2) achieving shared understanding of management of the medical condition, 3) offering important information, 4) enhancing the providerpatient relationship, and 5) awareness about resource distribution.

Assessment of patient preferences and communication of these to the provider is fundamental to the patient-centered care of nocturia. There are two main methods of assessing preferences: revealed and stated. Observational data related to a persons' actual behavior are used to determine revealed preference. The stated preference assessment depends on structured or hypothetical conditions. In this method, surveys are used to obtain data on patients' preferences for hypothetical experimental scenarios. Therefore, an important criterion of patient-centered nocturia care consists of recognizing the patient as a person and understanding the symptoms of nocturia (specifically bothers) from the patient's perspective. Therefore, future research needs to address these issues that appear to be stalemating the patient-centered care of nocturia.

\section{Nocturia-condition component}

Nocturia is common among older persons, and has an effect on morbidity and mortality. Among the elderly, the syndrome of nocturnal polyuria is a common reason for nocturia, and may be caused by the lower nocturnal secretion of antidiuretic hormone. Though the prevalence of nocturia in younger men and women is low, it can reach $80 \%-90 \%$ by 80 years of age. ${ }^{6,728}$ Nocturia can disrupt sleep, which in turn can lead to drowsiness during daytime, symptoms of depression, and weakened sense of wellness. ${ }^{31,44,49-53}$ Additionally, nocturia is shown to be linked with greater morbidity and mortality risk. Nocturia is the result of an intricate interaction of age-related changes in the function of urinary and renal systems, patterns of sleep, comorbidities, medications, and personal habits. Appropriate treatment necessitates correct identification of the underlying pathophysiologic cause of nocturia.

\section{Nocturia-treatment component}

Isolating the cause is the basic step in the treatment of nocturia. For some patients, treatments in the form of behavioral and lifestyle changes can be beneficial, while for others pharmacological treatment may be necessary. ${ }^{5,11,21,41,49,54-58}$ Just as with selecting the optimal treatment, it is essential to understand that nocturia is one of the reasons for sleep disorders. At the same time, it is important to acknowledge the limitations of drugs, as side effects may occur in spite of enhanced quality of life and sleep. ${ }^{49,50,59,60}$ New physiotherapy techniques to treat nocturia, overactive bladder, and urinary incontinence symptoms involve improving the awareness of overactivity in the pelvic floor and controlling the detrusor. ${ }^{31,33,52,53,61}$ The majority of therapies for nocturia have predominantly focused on or are related to overactive bladder care. One of the pharmacologic treatments involves the use of anticholinergics or antimuscarinics. However, these have very limited efficacy for nocturia, and may be appropriate for those without nocturnal polyuria and with severe urgency as the reason for awakening. ${ }^{62,63}$

Since most anticholinergics have such side effects as constipation and dryness of the mouth and eyes, other therapies that lack these side effects have been developed (eg, mirabegron, botulinum toxin, and vasopressin). In order to decrease involuntary detrusor contractions, the medication treatment for overactive bladder has mostly concentrated on blocking the postsynaptic muscarinic receptors on the detrusor muscle. At the same time, efficacy, acceptance, and adherence in the long run can affect the utilization of these medications. Earlier research on effects of botulinum-toxin treatment for nocturia has reported mixed results. ${ }^{14,64-67}$ Overall, insufficient symptom control, bother, unfulfilled or impractical expectations, and insufficient posttreatment follow-up are important contributors to medication nonadherence. ${ }^{68}$

\section{Social and economic component}

Social and economic factors that affect medication adherence are a patients' home environment, neighborhood structure, support level, and costs. ${ }^{5,12,43,46,69,70}$ Specifically, these factors are the living conditions of the patient, relationships he/she shares with the family and neighborhood, the magnitude of stress and violence in the neighborhood, and economic condition of the neighborhood. Other important socioeconomic factors that merit consideration in the context of medication 
adherence are travel distance, aging of the community, and race and ethnicity.

\section{Discussion}

A common and bothersome symptom, nocturia is associated with many health conditions. Given its chronic nature, nocturia symptoms can deteriorate in the absence of treatment, and health benefits could be higher with good adherence. . $2,31,33,52$ Several treatment options are available for nocturia, depending on the underlying cause. , $31,71,72^{\text {This }}$ review shows that both adherence to nocturia treatment and outcomes are complex and intertwined. Nonadherence to nocturia treatment is common. Though the burden exerted by nocturia is substantial, research indicates that a considerable proportion of nocturia patients cease pharmacological treatment. ${ }^{12,33,34,52,61,73,74}$ Association between adherence to nocturia treatment, side effects, and adverse events have been observed. ${ }^{6,41,49,57,75,76}$ Adverse events can affect the production of hormones that control diuresis and alter the structure of the lower urinary tract. Adverse events are most frequent in persons aged 65 years or older, women in the postmenopausal stage, and men with prostatic hyperplasia. Therefore, age has a strong association with nocturia. Multivariate analyses have indicated a strong association between better adherence and lower costs of care, after adjusting for demographic attributes and comorbidity. ${ }^{55}$ At the same time, there is uncertainty regarding the association between nocturia-induced sleep disruptions and frequent nighttime urination. Research indicates that nocturnal enuresis is a complex condition in children that is linked with abnormal sleep patterns and motor coordination, and visuomotor condition, disordered respiration, and mild reading difficulties. ${ }^{16-20,77,78}$

One important factor related to adherence is the bother of the symptoms. Although by definition, nocturia refers to at least one nighttime voiding, not all persons may find this bothersome. The degree of bother is subjective, and may change from person to person. Generally speaking, the higher the frequency, the more bothersome the symptoms. However, there is no information related to the association between bothers and adherence to medication or behavioral treatments. Behavioral modifications have been observed to work well. Unless the nocturia is associated with true severe nocturnal urgency, antimuscarinics or $\alpha$-adrenergic blocking agents are not effective. The "optimal medication" would be one that significantly decreases urine output, but for a very short period of time and without any chance of hyponatremia, which is the major cause of significant adverse events. Probably the most significant parameter to measure is the first period of uninterrupted sleep. Although there has been little research about what is the minimum for an ideal, most sleep experts estimate this at 240 minutes.

As with any other health conditions, adherence to medication is important in nocturia care to achieve improved patient functioning and quality of life. Factors that may influence adherence are the type of drug and its formulation, provider-level factors (ie, communication and attitude), and patient-level factors (ie, comorbidity, preference, access, cost, and family/social support). ${ }^{11,27,29,32,34,45,47-49,68,79-82}$ Additionally, these factors can have differing or additive effects. Current pharmacological treatments report rather weak side effects, and lower doses were observed to improve acceptability without affecting efficacy, especially among elderly patients with multiple chronic illnesses. 6 , $7,31,33,34,42,47,52,53,61,73,83,84$ For optimizing dosing and improving adherence, medication titration can be a useful approach. However, the association between dose titration and adherence remains to be established. Studies have reported that it is important to educate nocturia patients so that they do not accept their symptoms as an unavoidable aspect of aging, and also to increase their knowledge of the various treatments available to them. . $^{6,31,33,34,47,52,61,73,83}$ Patients who are offered educational intervention are significantly more likely to have their prescriptions filled and to accept behavior-modification treatments. ${ }^{57,69}$ Providers need to interact with those patients who are observed to be nonadherent. This will create an opportunity to understand the patients' treatment expectations, and at the same time educate the patient regarding available treatment options.

\section{Need for future research}

Despite the considerable effect of nocturia on patients' health and well-being, high rates of treatment interruption, and low medication adherence, only limited information exists regarding the overall implications of pharmacologic nonadherence for nocturia. ${ }^{1,61,73}$ Before any specific conclusions can be made regarding the immediate and long-term impact of medication adherence in nocturia patients, further research is necessary to: 1) develop agreement across various disciplines regarding the contribution made by each evaluation and diagnostic instrument in providing an accurate diagnosis of nocturia; 2) highlight the necessity of the appropriate assessment of nocturia tied to measurable outcomes; 3) systematically evaluate quality of life with validated tools, as well as sleep quality, level of bother, and health resource utilization and cost parameters, using population-based prospective studies (and clinical trials); 4) refine the role of behavioral therapies and assess the efficacy 
versus acceptability of their components in the management of nocturia; and 5) study the effect of adherence to nocturia medication on short- and long-term outcomes across various clinical settings.

\section{Disclosure}

The authors report no conflicts of interest in this work.

\section{References}

1. Osman NI, Chapple CR, Wein AJ. Nocturia: current concepts and future perspectives. Acta Physiol (Oxf). 2013;207:53-65.

2. Abrams P, Cardozo L, Fall M, et al. The standardisation of terminology of lower urinary tract function: report from the Standardisation Subcommittee of the International Continence Society. Neurourol Urodyn. 2002;21:167-178.

3. Weiss JP, Blaivas JG, Bliwise DL, et al. The evaluation and treatment of nocturia: a consensus statement. BJU Int. 2011;108:6-21.

4. Weiss JP, Blaivas JG, Blanker MH, et al. The New England Research Institutes, Inc. (NERI) Nocturia Advisory Conference 2012: focus on outcomes of therapy. BJU Int. 2013;111:700-716.

5. Bosch JL, Weiss JP. The prevalence and causes of nocturia. J Urol. 2012;189:S86-S92.

6. van Doorn B, Bosch JL. Nocturia in older men. Maturitas. 2012;71:8-12.

7. Goessaert AS, Denys MA, Deryckere S, Everaert K. Nocturnal polyuria in a nursing home and effect on quality of life. J Am Geriatr Soc. 2013;61:1812-1813.

8. Markland AD, Vaughan CP, Johnson TM 2nd, Goode PS, Redden DT, Burgio KL. Prevalence of nocturia in United States men: results from the National Health and Nutritional Examination Survey. J Urol. 2011; 185:998-1002.

9. van Kerrebroeck P, Abrams P, Chaikin D. The standardization of terminology in nocturia: report from the Standardisation Sub-committee of the International Continence Society. Neurourol Urodyn. 2002;21: 179-183.

10. Kerrebroeck PV, Andersson KE. Terminology, epidemiology, etiology, and pathophysiology of nocturia. Neurourol Urodyn. 2014;33:S2-S5.

11. Benner JS, Nichol MB, Rovner ES, et al. Patient-reported reasons for discontinuing overactive bladder medication. BJU Int. 2010;105: 1276-1282.

12. Kobelt G, Borgström F, Mattiasson A. Productivity, vitality and utility in a group of healthy professionally active individuals with nocturia. BJU Int. 2003;91:190-194.

13. Lose G, Lalos O, Freeman RM, van Kerrebroeck P. Efficacy of desmopressin (Minirin) in the treatment of nocturia: a double-blind placebo-controlled study in women. Am J Obstet Gynecol. 2003;189:1106-1113.

14. Weiss JP, Wein AJ, van Kerrebroeck P, et al. Nocturia: new directions. Neurourol Urodyn. 2011;30:700-703.

15. Bliwise DL, Rosen RC, Bau N. Impact of nocturia on sleep and quality of life: a brief, selected review for the International Consultation on Incontinence Research Society (ICI-RS) nocturia think tank. Neurourol Urodyn. 2014;33:S15-S18.

16. Carotenuto M, Esposito M, Pascotto A. Migraine and enuresis in children: an unusual correlation? Med Hypotheses. 2010;75:120-122.

17. Carotenuto M, Esposito M, Pascotto A. Facial patterns and primary nocturnal enuresis in children. Sleep Breath. 2011;15:221-227.

18. Esposito M, Carotenuto M, Roccella M. Primary nocturnal enuresis and learning disability. Minerva Pediatr. 2011;63:99-104.

19. Esposito M, Gallai B, Parisi L, et al. Primary nocturnal enuresis as a risk factor for sleep disorders: an observational questionnaire-based multicenter study. Neuropsychiatr Dis Treat. 2013;9:437-443.

20. Esposito M, Gallai B, Parisi L, et al. Visuomotor competencies and primary monosymptomatic nocturnal enuresis in prepubertal aged children. Neuropsychiatr Dis Treat. 2013;9:921-929.
21. Cornu JN, Abrams P, Chapple CR, et al. A contemporary assessment of nocturia: definition, epidemiology, pathophysiology, and managementa systematic review and meta analysis. Eur Urol. 2012;62:877-890.

22. Johnson TM 2nd, Burgio KL, Redden DT, Wright KC, Goode PS. Effects of behavioral and drug therapy on nocturia in older incontinent women. J Am Geriatr Soc. 2005;53:846-850.

23. Johnson TM 2nd, Markland AD, Goode PS, et al. Efficacy of adding behavioural treatment or antimuscarinic drug therapy to $\alpha$-blocker therapy in men with nocturia. BJU Int. 2013;112:100-108.

24. Johnson TM 2nd, Jones K, Williford WO, Kutner MH, Issa MM, Lepor H. Changes in nocturia from medical treatment of BPH. Secondary analysis of the VA Cooperative Study Trial. J Urol. 2003;170:140-148.

25. Mattiasson A, Abrams P, Van Kerrebroeck P, Walter S, Weiss J. Efficacy of desmopressin in the treatment of nocturia: a double-blind placebo-controlled study in men. BJU Int. 2002;89:855-862.

26. Osterberg L, Blaschke T. Adherence to medication. $N$ Engl J Med. 2005;353:487-497.

27. D’Souza AO, Smith MJ, Miller LA, Doyle J, Ariely R. Persistence, adherence, and switch rates among extended-release and immediaterelease overactive bladder medications in a regional managed care plan. J Manag Care Pharm. 2008;14:291-301.

28. Easterling SA, Master V, Carney KJ. Evaluation and management of patients with nocturia. JAAPA. 2014;27:36-42.

29. Yu YF, Nichol MB, Yu AP, Ahn J. Persistence and adherence of medications for chronic overactive bladder/urinary incontinence in the California Medicaid program. Value Health. 2005;8:495-505.

30. Pelletier EM, Vats V, Clemens MJ. Pharmacotherapy adherence and costs versus nonpharmacologic management in overactive bladder. $\mathrm{Am}$ J Manag Care. 2009;15:S108-S114.

31. Rosen RC, Holm-Larsen T, Kupelian V, Wein AJ. Consequences of nocturia. Postgrad Med. 2013;125:38-46.

32. Sears CL, Lewis C, Noel K, Albright TS, Fischer JR. Overactive bladder medication adherence when medication is free to patients. $J$ Urol. 2010;183:1077-1081.

33. Tikkinen KA, Auvinen A, Johnson TM 2nd, et al. A systematic evaluation of factors associated with nocturia - the population based FINNO study. Am J Epidemiol. 2009;170:361-368.

34. Veenboer PW, Bosch JL. Long-term adherence to antimuscarinic therapy in everyday practice: a systematic review. J Urol. 2010;191: 1003-1008.

35. Van Herzeele C, Alova I, Evans J, et al. Poor compliance with primary nocturnal enuresis therapy may contribute to insufficient desmopressin response. J Urol. 2009;182:2045-2049.

36. Gourova LW, van de Beek C, Spigt MG, Nieman FH, van Kerrebroeck PE. Predictive factors for nocturia in elderly men: a cross sectional study in 21 general practices. BJU Int. 2006;97:528-532.

37. Institute of Medicine of the National Academies. Crossing the Quality Chasm: A New Health System for the 21st Century. Washington: National Academies; 2001.

38. Andersen RM. Revisiting behavioral model and access to medical care: does it matter? J Health Soc Behav. 1995;36:1-10.

39. Aday LA, Andersen R. A framework for the study of access to medical care. Health Serv Res. 1974;9:208-220.

40. Murray MD, Morrow DG, Weiner M, et al. A conceptual framework to study medication adherence in older adults. Am J Geriatr Pharmacother. 2004;2:36-43.

41. Basra RK, Wagg A, Chapple C, et al. A review of adherence to drug therapy in patients with overactive bladder. BJU Int. 2008;102:774-779.

42. Yeaw J, Benner JS, Walt JG, Sian S, Smith DB. Comparing adherence and persistence across 6 chronic medication classes. J Manag Care Pharm. 2009;15:728-740.

43. Vecchioli Scaldazza C, Morosetti C, Pace G, Azizi B, Giannubilo W, Ferrara $\mathrm{V}$. Has the cost of anti-muscarinic a key role in the success rate of patients diagnosed with overactive bladder syndrome? Arch Ital Urol Androl. 2012;84:68-73.

44. Brubaker L, Fanning K, Goldberg EL, et al. Predictors of discontinuing overactive bladder medications. BJU Int. 2010;105:1283-1290. 
45. Gamble T, Sand P. Patient perspectives in the management of overactive bladder, focus on transdermal oxybutynin. Patient Prefer Adherence. 2008:2:349-356.

46. Shaya FT, Blume S, Gu A, Zyczynski T, Jumadilova Z. Persistence with overactive bladder pharmacotherapy in a Medicaid population. Am J Manag Care. 2005;11:S121-S129.

47. Robinson JH, Callister LC, Berry JA, Dearing KA. Patient-centered care and adherence: definitions and applications to improve outcomes. J Am Acad Nurse Pract. 2008;20:600-607.

48. Mead N, Bower P. Patient-centeredness: a conceptual framework and review of the empirical literature. Soc Sci Med. 2000;51:1087-1110.

49. Hofmeester I, Kollen BJ, Steffens MG, et al. The association between nocturia and nocturnal polyuria in clinical and epidemiological studies: a systematic review and meta analyses. J Urol. 2013;191:1028-1033.

50. Raheem OA, Orosco RK, Davidson TM, Lakin C. Clinical predictors of nocturia in the sleep apnea population. Urol Ann. 2014;6:31-35.

51. Song M, Hong BS, Chun JY, Han JY, Choo MS. Safety and efficacy of desmopressin for the treatment of nocturia in elderly patients: a cohort study. Int Urol Nephrol. 2014;46:1495-1499.

52. Tikkinen KA, Johnson TM 2nd, Tammela TL, et al. Nocturia frequency, bother, and quality of life: how often is too often? A population-based study in Finland. Eur Urol. 2010;57:488-498.

53. Yokoyama O, Hiro S, Hotta S, Mogami S, Yamagami H. Efficacy of fesoterodine on nocturia and quality of sleep in Asian patients with overactive bladder. Urology. 2014;83:750-755.

54. Aday LA, Andersen R. A framework for the study of access to medical care. Health Serv Res. 1974;9:208-220.

55. Balkrishnan R, Bhosle MJ, Camacho FT, Anderson RT. Predictors of medication adherence and associated health care costs in an older population with overactive bladder syndrome: a longitudinal cohort study. J Urol. 2006;175:1067-1072.

56. Breyer BN, Shindel AW, Erickson BA, Blaschko SD, Steers WD, Rosen RC. The association of depression, anxiety and nocturia: a systematic review. J Urol. 2013;190:953-957.

57. Chancellor MB, Migliaccio-Walle K, Bramley TJ, Chaudhari SL, Corbell C, Globe D. Long-term patterns of use and treatment failure with anticholinergic agents for overactive bladder. Clin Ther. 2013;35: 1744-1751.

58. Chung MS, Chuang YC, Lee JJ, Lee WC, Chancellor MB, Liu RT. Prevalence and associated risk factors of nocturia and subsequent mortality in 1,301 patients with type 2 diabetes. Int Urol Nephrol. 2014;46: 1269-1275.

59. Yoshimura K, Ohara H, Ichioka K, et al. Nocturia and benign prostatic hyperplasia. Urology. 2003;61:786-790.

60. Johnson TM 2nd, Burrows PK, Kusek JW, et al. The effect of doxazosin, finasteride and combination therapy on nocturia in men with benign prostatic hyperplasia. J Urol. 2007;178:2045-2050.

61. Weiss JP, Wein AJ, Van Kerrebroeck P. Future research guidance for nocturia. Neurourol Urodyn. 2014;33 Suppl 1:S25.

62. Rackley R, Weiss JP, Rovner ES, Wang JT, Guan Z. Nighttime dosing with tolterodine reduces overactive bladder-related nocturnal micturitions in patients with overactive bladder and nocturia. Urology. 2006;67: 731-736.

63. Brubaker L, FitzGerald MP. Nocturnal polyuria and nocturia relief in patients treated with solifenacin for overactive bladder symptoms. Int Urogynecol J Pelvic Floor Dysfunct. 2007;18:737-741.

64. Hirst GR, Watkins AJ, Guerrero K, et al. Botulinum toxin B is not an effective treatment of refractory overactive bladder. Urology. 2007;69: 69-73.

65. Schmid DM, Sauermann P, Werner M, et al. Experience with 100 cases treated with botulinum-A toxin injections in the detrusor muscle for idiopathic overactive bladder syndrome refractory to anticholinergics. Journal of Urology. 2006;176:177-185.
66. Apostolidis A, Dasgupta P, Denys P, et al. Recommendations on the use of botulinum toxin in the treatment of lower urinary tract disorders and pelvic floor dysfunctions: a European consensus report. Eur Urol. 2009;55:100-120.

67. Duthie JB, Vincent M, Herbison GP, Wilson DI, Wilson D. Botulinum toxin injections for adults with overactive bladder syndrome. Cochrane Database Syst Rev. 2011:(12)CD005493.

68. Weiss JP, Juul KV, Wein AJ. Management of nocturia: the role of antidiuretic pharmacotherapy. Neurourol Urodyn. 2014;33:S19-S24.

69. Chen FY, Dai YT, Liu CK, Yu HJ, Liu CY, Chen TH. Perception of nocturia and medical consulting behavior among community-dwelling women. Int Urogynecol J Pelvic Floor Dysfunct. 2007;18:431-436.

70. Sexton CC, Notte SM, Maroulis C, et al. Persistence and adherence in the treatment of overactive bladder syndrome with anticholinergic therapy: a systematic review of the literature. Int J Clin Pract. 2011;65: $567-585$.

71. Gulur DM, Mevcha AM, Drake MJ. Nocturia as a manifestation of systemic disease. BJU Int. 2010;107:702-713.

72. Nevéus T, Leissner L, Rudblad S, Bazargani F. Orthodontic widening of the palate may provide a cure for selected children with therapyresistant enuresis. Acta Paediatr. 2014;103:1187-1191.

73. van Kerrebroeck P. Nocturia: current status and future perspectives. Curr Opin Obstet Gynecol. 2011;23:376-385.

74. Wagg A, Compion G, Fahey A, Siddiqui E. Persistence with prescribed antimuscarinic therapy for overactive bladder: a UK experience. BJU Int. 2012;110:1767-1774.

75. Eisenhardt A, Schneider T, Cruz F, Oelke M. Consistent and significant improvement of nighttime voiding frequency (nocturia) with silodosin in men with LUTS suggestive of BPH: pooled analysis of three randomized, placebo-controlled, double-blind phase III studies. World J Urol. 2014;32:1119-1125.

76. Asplund R. Pharmacotherapy for nocturia in the elderly patient. Drugs Aging. 2007;24:325-343.

77. Nevéus T, Leissner L, Rudblad S, Bazargani F. Respiration during sleep in children with therapy-resistant enuresis. Acta Paediatr. 2014;103: 300-304.

78. Cederblad M, Sarkadi A, Engvall G, Nevéus T. Infrequent enuresis, the uninvestigated majority comparisons between children with enuresis of varying severity. J Pediatr Urol. Epub ahead of print; 2014.

79. Gomelsky A, Dmochowski RR. Update on the management of overactive bladder: patient considerations and adherence. Open Access J Urol. 2010;3:7-17.

80. Johnston S, Janning SW, Haas GP, et al. Comparative persistence and adherence to overactive bladder medications in patients with and without diabetes. Int J Clin Pract. 2012;66:1042-1051.

81. Haa F, Castro-Diaz D. Persistence with antimuscarinic therapy in patients with overactive bladder. Int J Clin Pract. 2005;59:931-937.

82. Hampel C. Long-term management of overactive bladder with antimuscarinic agents. Eur Urol Suppl. 2007;6:432-437.

83. Mobley DF, Baum N. Etiology, evaluation, and management of nocturia in elderly men and women. Postgrad Med. 2014;126:147-153.

84. Jundt K, Schreyer K, Friese K, Peschers U. Anticholinergic therapy: do the patients take the pills prescribed? Arch Gynecol Obstet. 2011;284: 663-666.

85. Filipetto FA, Fulda KG, Holthusen AE, McKeithen TM, McFadden P. The patient perspective on overactive bladder: a mixed methods needs assessment. BMC Fam Pract. 2014;15:96.

86. Mauseth SA, Skurtveit S, Spigset O. Adherence, persistence and switch rates for anticholinergic drugs used for overactive bladder in women: data from the Norwegian Prescription Database. Acta Obstet Gynecol Scand. 2013;92:1208-1215. 
Patient Preference and Adherence

Dovepress

\section{Publish your work in this journal}

Patient Preference and Adherence is an international, peer-reviewed, open access journal that focuses on the growing importance of patient preference and adherence throughout the therapeutic continuum. Patient satisfaction, acceptability, quality of life, compliance, persistence and their role in developing new therapeutic modalities and compounds to optimize

Submit your manuscript here: http://www.dovepress.com/patient-preference-and-adherence-journ clinical outcomes for existing disease states are major areas of interest for the journal. This journal has been accepted for indexing on PubMed Central. The manuscript management system is completely online and includes a very quick and fair peer-review system, which is all easy to use. Visit http://www. dovepress.com/testimonials.php to read real quotes from published authors. 